\title{
Sex differences in physiological progression of idiopathic pulmonary fibrosis
}

\author{
M.K. Han*, S. Murray*, C.D. Fell”, K.R. Flaherty*, G.B. Toews*, J. Myers*, T.V. Colbyף, \\ W.D. Travis ${ }^{+}$, E.A. Kazerooni*, B.H. Gross* and F.J. Martinez*
}

\begin{abstract}
In idiopathic pulmonary fibrosis, incidence is higher in males, and females may have better survival. The aim of the present study was to determine whether the rate of increase in desaturation during serial 6-min walk testing would be greater, and survival worse, for males versus females.
\end{abstract}

Serial changes in the percentage of maximum desaturation area (DA) over 1 yr were estimated using mixed models in $\mathbf{2 1 5}$ patients. DA was defined as the total area above the curve created using desaturation percentage values observed during each minute of the 6-min walk test. Multivariate Cox regression assessed survival differences.

Adjusting for baseline DA, 6-min walk distance, change in 6-min walk distance over time and smoking history, the percentage of maximum DA increased by an average of 2.83 and $1.37 \%$ per month for males and females, respectively. Females demonstrated better survival overall, which was more pronounced in patients who did not desaturate below $88 \%$ on ambulation at baseline and after additionally adjusting for 6-month relative changes in DA and forced vital capacity.

These data suggest that differences in disease progression contribute to, but do not completely explain, better survival of females with idiopathic pulmonary fibrosis.

\section{KEYWORDS: Desaturation, interstitial lung disease, 6-min walk test, survival}

diopathic pulmonary fibrosis (IPF) is a diffuse parenchymal lung disease of unknown origin, characterised by alveolar inflammation, fibrosis of the interstitial space and pulmonary vascular disruption. Sex discrepancies in this disorder have been suggested for some time. The incidence and prevalence of disease have been reported in multiple studies to be higher in males than in females, with ratios ranging from $\sim 1.6: 1$ to $2: 1$ [1-3]. Prior reports have also suggested that the female sex is associated with better survival $[4,5]$. The current hypothesis was that the rate of physiological progression of disease, as measured by serial progression in exertional oxygen desaturation, would be greater in males than females. It has previously been demonstrated that oxygen desaturation and serial increases in desaturation during 6-min walk tests (6MWTs) in IPF patients correlate with increased mortality [6]; therefore, the present authors also wanted to assess whether sex differences in survival remained after adjusting for longitudinal change in desaturation.

\section{MATERIALS AND METHODS}

\section{Study subjects}

The present study utilised patients in the database of the University of Michigan Specialized
Center of Research (Ann Arbor, MI, USA) in the Pathobiology of Fibrotic Lung Disease. Patients in this database were referred for enrolment in study protocols for suspected IPF based on typical symptoms, and physiological and radiographical findings. Patients with a high-resolution computed tomography (HRCT) scan showing a definite pattern of usual interstitial pneumonia (UIP) were not required to undergo a surgical lung biopsy [7-10]. Patients were treated with varied treatment regimens, which included the following: no therapy; prednisone alone; prednisone with an additional immunosuppressive agent, including azathioprine, cyclophosphamide, methotrexate or mycophenolate mofetil; investigational agents, including bosentan, interferon- $\gamma$, GC1008 anti-transforming growth factor- $\beta$ antibody, pirfenidone, tetrathiomolybdate or zileuton; or miscellaneous agents, including $N$ acetylcysteine or colchicine (table 1). Therapy decisions were made by the treating clinician. The lack of a prospectively defined treatment regimen, varying lengths of therapy and the overlap of treatment regimens precluded the ability to evaluate the effect of treatment on serial change in pulmonary function, 6MWT or survival; there is little evidence to date that any of these treatments were effective in improving outcomes.
AFFILIATIONS

*University of Michigan Health

System, Ann Arbor, MI,

"Mayo Clinic, Scottsdale, AZ,

+Memorial Sloan Kettering Cancer

Center, New York, NY, USA.

\#University of Calgary, Calgary, $A B$ Canada.

CORRESPONDENCE

M.K. Han

1500 E Medical Center Drive

3916 Taubman Center

Ann Arbor

Ml 48109-0360

USA

Fax: 17349365048

E-mail: mrking@umich.edu

Received:

December 062007

Accepted:

February 132008

SUPPORT STATEMENT

This work was supported by National Institutes of Health grants 5P50HL56402, U10HL080371, 2K24HL04212, K12RR024987 and K23HL68713, and the Alberta Heritage Medical Foundation.

STATEMENT OF INTEREST None declared. 


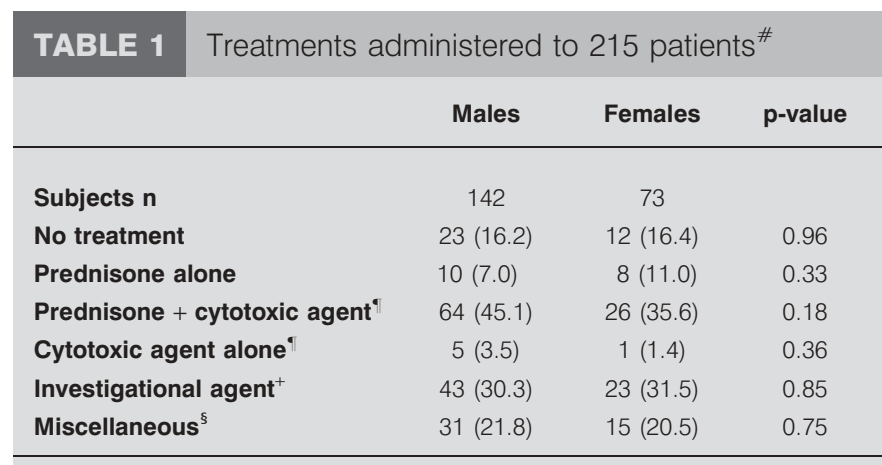

Data are presented as $n(\%)$, unless otherwise stated. ${ }^{*}$ : some patients received more than one treatment regimen, so total is $>100 \%$; ': azathioprine, cyclophosphamide, methotrexate or mycophenolate mofetil; ${ }^{+}$: bosentan, interferon- $\gamma$, GC1008 anti-transforming growth factor- $\beta$ antibody, pirfenidone, tetrathiomolybdate, or zileuton; ${ }^{\varsigma}$ : $\mathrm{N}$-acetylcysteine or colchicine.

In total, 10 of the patients (nine males and one female) eventually underwent lung transplantation. Patients with underlying connective tissue disease, obvious occupational exposure or a histopathologic pattern other than UIP were excluded. Approval for the use of these data was obtained from the Institutional Review Board of the University of Michigan (Ann Arbor). A subgroup of these patients has been previously described $[6,7,10-14]$.

\section{Study design}

The study consisted of a mixed models analysis to determine whether exertional hypoxaemia in IPF deteriorates more rapidly in males than females, adjusting for baseline desaturation area (DA), baseline 6MWT distance (6MWD), change in 6MWD over time and smoking history. Several survival models were also constructed, initially adjusting for age, smoking history, baseline DA and diffusing capacity of the lung for carbon monoxide (DL,CO) \% predicted. In a subset of physiologically milder patients who did not desaturate below $88 \%$ pred during the baseline $6 \mathrm{MWT}$, a 6 -month relative

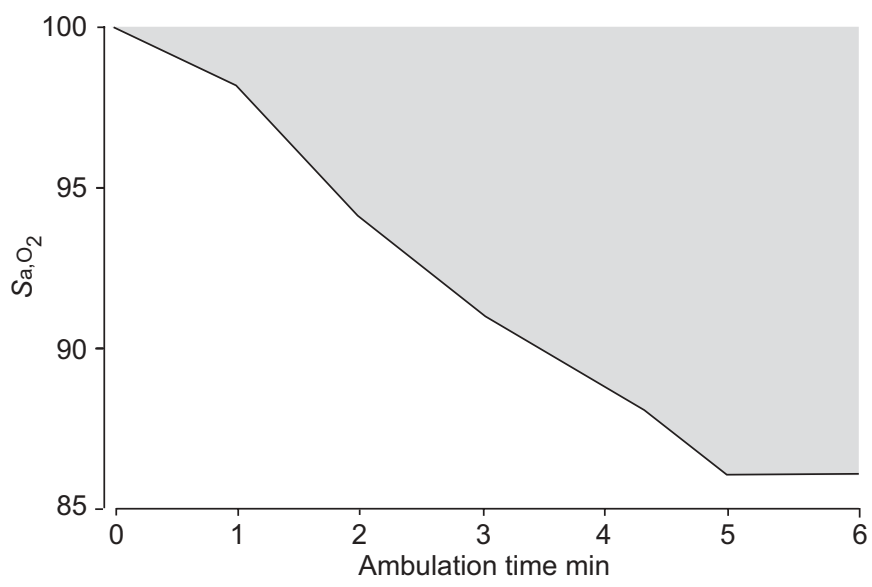

FIGURE 1. Schematic showing calculation of desaturation area. $\mathrm{Sa}, \mathrm{O}_{2}$ : arterial oxygen saturation. 1 : desaturation area. Reproduced and modified from [6] with permission from the publisher. change in both DA and forced vital capacity (FVC) \% pred was also included.

\section{Methods}

DA was defined as the total area above the curve created using desaturation percentage values observed during each minute of the 6MWT, thereby summing up the differences between an arterial oxygen saturation $\left(\mathrm{Sa}_{2} \mathrm{O}_{2}\right)$ of $100 \%$ and the patient's $\mathrm{Sa}, \mathrm{O}_{2}$ at each minute (fig. 1) [6]. For example, a patient with an $\mathrm{Sa}, \mathrm{O}_{2}$ of $98 \%$ at each minute during the $6 \mathrm{MWT}$ would have a DA of $12((100-98) \times 6=12)$. For safety, the $6 \mathrm{MWT}$ was stopped when patients reached an $\mathrm{Sa}_{2} \mathrm{O}_{2}$ of $86 \%$, and a desaturation score of $14 \%$ was assigned for that minute and all subsequent minutes of the 6MWT; thus, the maximum possible DA score (DAmax) for an individual is $14 \times 6=84$. A higher DA indicates higher overall quantity of desaturation during the $6 \mathrm{MWT}$.

\section{Statistical analysis}

Baseline characteristics were compared using an unpaired twosample t-test. The mixed models analysis was performed using PROC MIXED (SAS 9.1.2; SAS Institute Inc., Cary, NC, USA), which adjusts appropriately for missing data due to attrition. In this mixed model, all DA values were divided by 84 (DAmax) and multiplied by 100 , so that parameters estimate change in the \% DAmax. In order to assess survival differences between males and females, multivariate Cox regression models were used. Follow-up time was based on date of diagnosis, either by open lung biopsy or diagnostic HRCT. An initial survival analysis, adjusting for sex, age, baseline DA, $D \mathrm{~L}, \mathrm{CO} \%$ pred and smoking status, was performed in 179 patients with available data. Additional analyses were then performed on the 103 patients who did not desaturate below $88 \%$ on the baseline $6 \mathrm{MWT}$. Following this, a subset of those patients in whom serial $6 \mathrm{MWT}$ data were available $(n=72)$ was

\begin{tabular}{|c|c|c|c|}
\hline \multirow[t]{2}{*}{ TABLE 2} & \multirow[b]{2}{*}{ Males } & \multirow[b]{2}{*}{ Females } & \multirow[b]{2}{*}{ p-value } \\
\hline & & & \\
\hline Subjects $\mathrm{n}$ & 142 & 73 & \\
\hline Age yrs & 63.0 & 64.2 & 0.39 \\
\hline Baseline DA (\% DAmax) & $59.0(70.2)$ & $60.1(71.5)$ & 0.81 \\
\hline Baseline desaturation $<88 \%{ }^{\#}$ & 37.3 & 35.6 & 0.68 \\
\hline FVC \% pred & 64.7 & 65.8 & 0.68 \\
\hline DL,Co \% pred & 44.0 & 44.9 & 0.73 \\
\hline Arterial blood pH & 7.42 & 7.43 & 0.64 \\
\hline $\mathrm{Pa}, \mathrm{CO}_{2} \mathrm{mmHg}$ & 38.8 & 38.6 & 0.79 \\
\hline $\mathrm{Pa}, \mathrm{O}_{2} \mathrm{mmHg}$ & 75.1 & 73.5 & 0.17 \\
\hline Resting $\mathrm{Sa}, \mathrm{O}_{2} \%$ & 94.3 & 94.5 & 0.81 \\
\hline 6MWD m & 275.1 & 240.1 & 0.18 \\
\hline Former or current smoker $\%$ & 82.4 & 63.0 & 0.002 \\
\hline \multicolumn{4}{|c|}{$\begin{array}{l}\text { Data are means, unless otherwise stated. DA: desaturation area; \% DAmax: } \\
\text { percentage of maximum possible DA score of } 84 \text {; FVC: forced vital capacity; } \\
\% \text { pred: \% predicted; } \mathrm{DL}, \mathrm{CO} \text { : diffusing capacity of the lung for carbon monoxide; } \\
\mathrm{Pa}_{1} \mathrm{CO}_{2} \text { : arterial carbon dioxide tension; } \mathrm{Pa}_{1} \mathrm{O}_{2} \text { : arterial oxygen tension; } \mathrm{Sa}, \mathrm{O}_{2} \text { : } \\
\text { arterial oxygen saturation; } 6 \mathrm{MWD:} 6 \text {-min walk distance. }{ }^{\#} \text { : percentage of } \\
\text { patients. } 1 \mathrm{mmHg}=0.133 \mathrm{kPa} \text {. }\end{array}$} \\
\hline
\end{tabular}




\begin{tabular}{|c|c|c|}
\hline Predictor variable & Change in \% DAmax & p-value \\
\hline Time if male months & 2.83 & $<0.0001$ \\
\hline Time if female months & 1.37 & 0.01 \\
\hline Female & -1.25 & $0.14^{\circ}$ \\
\hline Interaction between distance walked and time $m$ per month & -0.006 & $<0.0001^{+}$ \\
\hline Former or current smoker versus nonsmoker & 0.49 & 0.59 \\
\hline
\end{tabular}

examined. For each of these patients, a 6-month predicted DA value was obtained from individual regression lines, provided that each patient was able to perform at least two 6MWTs within the first 12 months of follow-up and was still alive at the 6-month time mark. Relative change in DA was calculated by subtracting the baseline value from the 6-month predicted value and dividing by the baseline value, with follow-up commencing at the moment a patient trajectory became available for analysis. This method was also used to calculate 6-month relative change in FVC \% pred. Sex-specific survival curves were constructed, adjusting for the average values of 6month relative change in DA, baseline DA, age, smoking history, DL,CO \% pred, FVC \% pred and 6-month relative change in FVC \% pred. In all of the survival analyses, two mortality end-points were considered: 1) death following diagnosis, regardless of transplant status; and 2) death following diagnosis, with censoring at time of transplant.

\section{RESULTS}

\section{Baseline characteristics}

Baseline demographic data for all 215 patients are presented in table 2. There was no significant difference in most baseline variables except the percentage of males versus females who were former or current smokers. Due to this, the rest of the analyses were adjusted for smoking history.

\begin{tabular}{llc} 
TABLE 4 & $\begin{array}{l}\text { Multivariate survival model examining the impact } \\
\text { of sex }\end{array}$ & p-value \\
\hline Variable & HR (95\% Cl) & 0.04 \\
\hline & $0.63(0.41-0.97)$ & 0.04 \\
Female & $1.00(1.00-1.05)$ & 0.03 \\
Age yrs & $0.18(0.04-0.82)$ & 0.009 \\
DL,co \% pred & $1.02(1.00-1.03)$ & 0.80 \\
Desaturation area & $1.06(0.68-1.65)$ & \\
Former or current smoker & & \\
\hline &
\end{tabular}

\section{Repeated measures analysis}

Males were associated with a more rapid increase in DA over time compared with females, with the \% DAmax increasing by $2.83 \%$ per month for males versus $1.37 \%$ per month for females. Thus, after $1 \mathrm{yr}$, the sex difference in \% DAmax was $17.5 \%$ $(p=0.01)$. This indicates that the progression of exertional hypoxaemia was more rapid in males (table 3 ).

\section{Survival analysis}

A multivariate Cox regression model evaluating sex differences, adjusted for age, smoking history, DL,CO \% pred and DA, demonstrated a statistically significant survival advantage for females (hazard ratio (HR) 0.63 (95\% confidence interval (CI) $0.41-0.97) ; \mathrm{p}=0.04$; table 4). When FVC \% pred was included in the multivariate model, it was found to be a nonsignificant predictor of survival, and the corresponding sex HR continued to favour females $(p=0.048)$. Censoring these patients at the time of transplant did not substantially change the results $(0.61(0.39-0.94) ; \mathrm{p}=0.03)$.

Additionally, the impact of sex on patients with less severe disease was examined, since it is in these patients that there would be the most opportunity for exertional hypoxaemia to change over time and subsequently influence survival. Therefore, a survival analysis was performed on 103 patients

TABLE 5 Multivariate survival model examining the impact of sex in patients who did not desaturate below $88 \%$ during baseline 6-min walk test ${ }^{\#}$

\begin{tabular}{lcc} 
Variable & HR (95\% CI) & p-value \\
\hline Female & $0.48(0.26-0.89)$ & 0.02 \\
Age yrs & $1.03(0.99-1.06)$ & 0.11 \\
DL,co \% pred & $0.20(0.03-1.26)$ & 0.09 \\
Desaturation area & $1.03(1.01-1.04)$ & 0.001 \\
Former or current smoker & $1.02(0.57-1.82)$ & 0.95 \\
\hline
\end{tabular}

Analysis adjusted for age, diffusing capacity of the lung for carbon monoxide $(D L, C O) \%$ predicted (\% pred), desaturation area and smoking history. HR: hazard ratio; $\mathrm{Cl}$ : confidence interval. ${ }^{*}: \mathrm{n}=103$. 


\begin{tabular}{|c|c|c|c|}
\hline \multirow{2}{*}{$\begin{array}{l}\text { TABLE } 6 \\
\text { Variable }\end{array}$} & \multicolumn{3}{|c|}{$\begin{array}{l}\text { Multivariate survival model examining the impact } \\
\text { of sex in patients who did not desaturate below } \\
88 \% \text { during baseline } 6 \text {-min walk test (6MWT) and } \\
\text { in whom } 6 \mathrm{MWT} \text { trajectory data were available }\end{array}$} \\
\hline & & $\mathrm{HR}(95 \% \mathrm{Cl})$ & p-value \\
\hline \multicolumn{2}{|l|}{ Female } & $0.38(0.15-0.95)$ & 0.04 \\
\hline \multicolumn{2}{|l|}{ Age yrs } & $1.02(1.02-0.99)$ & 0.23 \\
\hline \multicolumn{2}{|c|}{$D L, C o$ \% pred } & $2.93(0.20-41.9)$ & 0.43 \\
\hline \multicolumn{2}{|c|}{ Desaturation area } & $1.05(1.02-1.08)$ & 0.0006 \\
\hline \multicolumn{2}{|c|}{ 6-month relative change in DA } & $2.91(1.51-5.60)$ & 0.001 \\
\hline \multicolumn{2}{|c|}{ Former or current smoker } & $0.71(0.28-1.79)$ & 0.43 \\
\hline \multicolumn{2}{|l|}{ FVC \% pred } & $0.35(0.05-2.53)$ & 0.30 \\
\hline \multicolumn{2}{|c|}{ 6-month relative change in FVC $\%$ pred } & $1.57(1.15-2.13)$ & 0.004 \\
\hline \multicolumn{4}{|c|}{$\begin{array}{l}\text { Analysis adjusted for age, diffusing capacity of the lung for carbon monoxide } \\
\text { (DL,CO) \% predicted (\% pred), desaturation area (DA), } 6 \text {-month relative change } \\
\text { in DA, smoking history, forced vital capacity (FVC) \% pred, and 6-month relative } \\
\text { change in FVC. HR: hazard ratio; Cl: confidence interval. }{ }^{\#:} n=72 \text {. }\end{array}$} \\
\hline
\end{tabular}

who did not desaturate below $88 \%$ during their first $6 \mathrm{MWT}$. In this analysis, the better survival of females was even more pronounced than in the overall patient population $(0.48(0.26-$ $0.89) ; p=0.02$; table 5) and remained marginally significant at the same order of clinical significance, when censoring patients at time of transplant $(0.57(0.31-1.05) ; \mathrm{p}=0.07)$.

Following this, 6-month relative change in DA, baseline FVC \% pred and 6-month relative change in FVC \% pred were added to the model ( $n=72$; table 6$)$, as increase in DA and decrease in FVC have been previously demonstrated to be predictive of survival in IPF [6]. In this model, the female sex was still associated with better survival (0.38 (0.15-0.95); $\mathrm{p}=0.04)$.

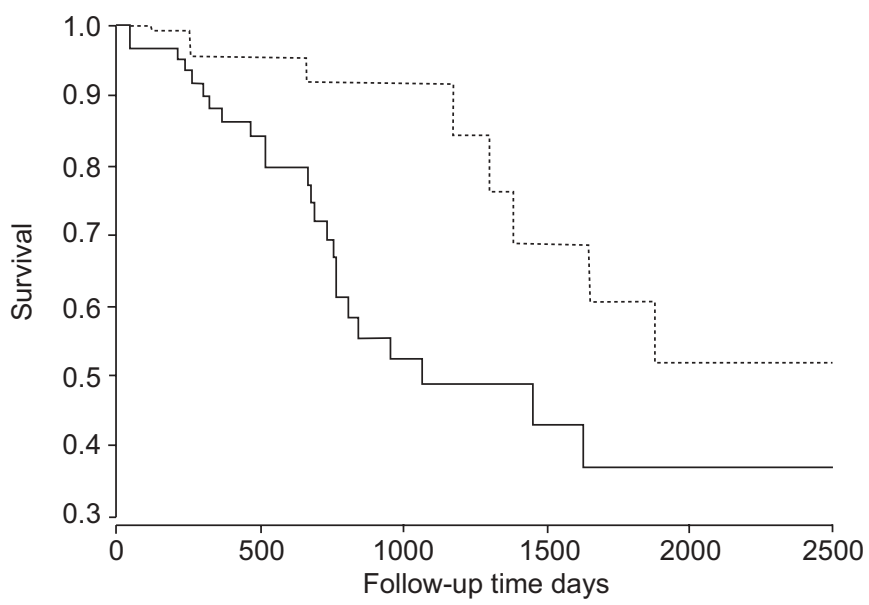

FIGURE 2. Comparison of survival between males $(-)$ and females $($ (…….) with idiopathic pulmonary fibrosis who did not desaturate below $88 \%$ on baseline 6 -min walk test $(n=72)$, adjusted for the following mean values: age $=62.85 \mathrm{yrs}$; diffusing capacity of the lung for carbon monoxide $=48.3 \%$ predicted; baseline desaturation area $(\mathrm{DA})=47.52$; 6-month relative change in DA as a percentage of baseline $=15.1 \%$; probability of smoking history $=77 \%$; baseline forced vital capacity $(\mathrm{FVC})=71 \%$ pred; and 6 -month relative change in $\mathrm{FVC} \%$ pred as a percentage of baseline $=5.2 \%$.
Baseline DA, 6-month relative change in DA and 6-month relative change in FVC were also significant independent predictors of survival in this model. Adjusted survival curves are presented in figure 2 for the average profile patient, similar except with regard to sex: age $=62.85$ yrs; $D \mathrm{~L}, \mathrm{CO}=48.3 \%$ pred; baseline $\mathrm{DA}=47.52$ (56.57\% of DAmax); 6-month relative change in DA as a percentage of baseline $=15.1 \%$; probability of smoking history $=77 \% ; \mathrm{FVC}=71 \%$ pred; and 6-month relative change in FVC \% pred as a percentage of baseline $=5.2 \%$. Notably, only one patient in this group underwent transplant during the follow-up period, and censoring that patient at the time of transplant did not substantially change the results of the analysis.

\section{DISCUSSION}

Sex discrepancies in IPF have been suggested by several investigators. These differences include a higher prevalence of disease and higher mortality in males. Since it has been suggested that serial measures of pulmonary physiology, particularly exertional desaturation, strongly influence survival in IPF, the current authors hypothesised that the rate of physiological progression of disease would be greater in males than females. In this study several important observations were made, including: 1) males with IPF demonstrate more rapid deterioration in exertional desaturation over time compared with females; 2) survival is worse in males compared with females; and 3) better survival for females persists after additional adjustment for relative change in exertional desaturation and FVC \% pred.

The importance of longitudinal change in FVC, DL,CO and $6 \mathrm{MWT}$ has been confirmed by several groups $[6,15,16]$, but sex differences in longitudinal change in physiological parameters have not been formerly reported. Thus, the present study explored and documented a sex difference in the rate of deterioration in exertional desaturation. While it could be argued that the difference in physiological trajectories was due to systematic differences in disease stage, there was no significant difference in baseline pulmonary function measurements or DA between sexes, and the change in DA over time was adjusted for age, smoking history, DL,CO \% pred and baseline DA. The aetiology of the sex-specific difference in disease progression, however, is not readily obvious.

The current study also demonstrates better survival of females with IPF compared with males, after adjusting for age, smoking history, DL,CO \% pred and DA. This is in contrast to a lesser-powered retrospective analysis of 99 patients with IPF, where sex was not detected to be a significant predictor of survival in a multivariate analysis adjusted for measures of lung function, age and smoking history [17]. In older literature, several studies suggest a survival advantage for females $[3,18]$ and several do not $[19,20]$, but this may be due to lack of power and a mixture of diagnoses prior to the development of the clinical, radiological and pathological diagnostic methods now in place. However, most recent reports suggest a survival advantage for females, with relative risks of death for males compared with females ranging 1.4-2.3 [4, 5].

Vital statistics in the USA indicate that the unadjusted average life expectancy for males is $74.7 \mathrm{yrs}$ and for females $80 \mathrm{yrs}$ [21]. In the present study, physiological parameters known to 
influence survival in IPF were controlled for, and significant differences in survival between males and females were still seen, well beyond the magnitude of survival differences seen in the general population. Interestingly, in the current subjects who did not desaturate below $88 \%$ on the baseline $6 \mathrm{MWT}$, the survival advantage for females was even more pronounced. The data are also strengthened by the rigorous definition of UIP using a clinical, radiographical and pathological format.

As DA trajectory and survival both differed between sexes, the hypothesis was also tested that relative change in DA may influence survival and help to explain sex differences. For this, the focus was on those patients with oxygen saturation above $88 \%$ during their baseline $6 \mathrm{MWT}$ and in whom serial $6 \mathrm{MWT}$ data were available. Specific examination of this group was chosen because these patients have less severe disease and, thus, theoretically more room to deteriorate during the observation period of the study, allowing better evaluation of how change in physiology affects survival. In the present survival analysis, FVC \% pred and 6-month relative change in $\mathrm{FVC} \%$ pred were also included in the model, as change in FVC has been previously shown to be a significant predictor of survival [6]. Other predictors included sex, age, smoking history and $D \mathrm{~L}, \mathrm{CO} \%$ pred. The survival advantage for females became even more pronounced (HR 0.38 (95\% CI 0.15-0.95); $\mathrm{p}=0.04$ ). Consequently, these data suggest that, while differences in disease progression probably contribute to better survival for females, the female sex is still associated with enhanced survival, independent of relative change in DA and FVC. A smaller series of IPF patients did not suggest that sex affected the predictive value of longitudinal change in exertional desaturation on survival [22]. Differences may reflect reduced power due to sample size or methodology used to define 6MWT desaturation. Additional prospective data collection is required to better define these differences.

Importantly, IPF is not the only fibrotic disorder in which sexual dimorphism has been noted. Females are relatively protected from fibrotic diseases involving the liver and kidney. Males with chronic renal disease progress more rapidly than females to end-stage renal failure [23]. Population data also suggest end-stage liver disease, in the form of cirrhosis, is much more common in males than females (ranging from 2.3:1 to 2.6:1) [24]. In both end-stage renal and hepatic disease, a potential role for oestrogen has been proposed, which appears to be protective in animal models [25-27]. The average age of females in the present study was 64.2 yrs, suggesting that the majority of females would have been post-menopausal, with low oestrogen levels. Conversely, a prior report of bleomycininduced pulmonary fibrosis in rats demonstrated diminished fibrosis in female ovariectomised rats; the fibrotic response was restored with oestradiol replacement [28]. Thus, an exact explanatory mechanism for the present data is not readily obvious, and the role of oestrogen on the fibrotic process must be further clarified. Better understanding of sex differences in disease progression may offer further insight into the pathogenesis of the disease.

There are limitations to the current study. The data are retrospective and potentially subject to several types of bias. Treatments were not systematically assigned. One sex may tend to present at different stages of the disease compared with the other, although this was not readily apparent in the present cohort, based on predictors studied as part of table 2 . While females tend to be more frequent seekers of healthcare in general, they are also less likely to receive subspecialty referrals [29]. Furthermore, the survival data may be biased by a differential presence of comorbidities, such as cardiovascular disease. The development of pulmonary vasculopathy was not prospectively assessed, which may be important as desaturation has been suggested to be associated with a greater prevalence of pulmonary hypertension in IPF patients [30]. A strength of the present study, however, is that the longitudinal analysis of DA was adjusted for factors that could potentially bias the results, including baseline DA, distance walked, change in distance walked over time, age and smoking status. Furthermore, patient diagnosis was assigned based on the current standard of care, a multidisciplinary clinical, radiological and pathological process.

In conclusion, the current study has determined that while differences in the rate of physiological progression probably contribute to survival differences between males and females, there may be other uncharacterised sex-related influences on survival. Prospective validation of the data is required to define potential therapeutic implications of these data.

\section{REFERENCES}

1 Carrington CB, Gaensler EA, Coutu RE, FitzGerald MX, Gupta RG. Natural history and treated course of usual and desquamative interstitial pneumonia. N Engl J Med 1978; 298: 801-809.

2 Raghu G, Weycker D, Edelsberg J, Bradford WZ, Oster G. Incidence and prevalence of idiopathic pulmonary fibrosis. Am J Respir Crit Care Med 2006; 174: 810-816.

3 Turner-Warwick M, Burrows B, Johnson A. Cryptogenic fibrosing alveolitis: clinical features and their influence on survival. Thorax 1980; 35: 171-180.

4 Mannino DM, Etzel RA, Parrish RG. Pulmonary fibrosis deaths in the United States, 1979-1991. An analysis of multiple-cause mortality data. Am J Respir Crit Care Med 1996; 153: 1548-1552.

5 Gribbin J, Hubbard RB, Le Jeune I, Smith CJ, West J, Tata LJ. Incidence and mortality of idiopathic pulmonary fibrosis and sarcoidosis in the UK. Thorax 2006; 61: 980-985.

6 Flaherty KR, Andrei AC, Murray S, et al. Idiopathic pulmonary fibrosis: prognostic value of changes in physiology and six-minute-walk test. Am J Respir Crit Care Med 2006; 174: 803-809.

7 Flaherty KR, Mumford JA, Murray S, et al. Prognostic implications of physiologic and radiographic changes in idiopathic interstitial pneumonia. Am J Respir Crit Care Med 2003; 168: 543-548.

8 Hunninghake GW, Lynch DA, Galvin JR, et al. Radiologic findings are strongly associated with a pathologic diagnosis of usual interstitial pneumonia. Chest 2003; 124: 1215-1223.

9 American Thoracic Society. Idiopathic pulmonary fibrosis: diagnosis and treatment. International consensus statement. American Thoracic Society (ATS), and the European Respiratory Society (ERS). Am J Respir Crit Care Med 2000; 161: 646-664. 
10 Flaherty KR, King TE Jr, Raghu G, et al. Idiopathic interstitial pneumonia: what is the effect of a multidisciplinary approach to diagnosis? Am J Respir Crit Care Med 2004; 170: 904-910.

11 Flaherty KR, Toews GB, Travis WD, et al. Clinical significance of histological classification of idiopathic interstitial pneumonia. Eur Respir J 2002; 19: 275-283.

12 Lama VN, Flaherty KR, Toews GB, et al. Prognostic value of desaturation during a 6-minute walk test in idiopathic interstitial pneumonia. Am J Respir Crit Care Med 2003; 168: 1084-1090.

13 Flaherty KR, Thwaite EL, Kazerooni EA, et al. Radiological versus histological diagnosis in UIP and NSIP: survival implications. Thorax 2003; 58: 143-148.

14 Flaherty KR, Travis WD, Colby TV, et al. Histopathologic variability in usual and nonspecific interstitial pneumonias. Am J Respir Crit Care Med 2001; 164: 1722-1727.

15 Collard HR, King TE Jr, Bartelson BB, Vourlekis JS, Schwarz MI, Brown KK. Changes in clinical and physiologic variables predict survival in idiopathic pulmonary fibrosis. Am J Respir Crit Care Med 2003; 168: 538-542.

16 Jegal Y, Kim DS, Shim TS, et al. Physiology is a stronger predictor of survival than pathology in fibrotic interstitial pneumonia. Am J Respir Crit Care Med 2005; 171: 639-644.

17 Erbes R, Schaberg T, Loddenkemper R. Lung function tests in patients with idiopathic pulmonary fibrosis. Are they helpful for predicting outcome? Chest 1997; 111: 51-57.

18 Schwartz DA, Helmers RA, Galvin JR, et al. Determinants of survival in idiopathic pulmonary fibrosis. Am J Respir Crit Care Med 1994; 149: 450-454.

19 Tukiainen P, Taskinen E, Holsti P, Korhola O, Valle M. Prognosis of cryptogenic fibrosing alveolitis. Thorax 1983; 38: 349-355.
20 Stack BH, Choo-Kang YF, Heard BE. The prognosis of cryptogenic fibrosing alveolitis. Thorax 1972; 27: 535-542.

21 Arias E. United States life tables, 2003. Natl Vital Stat Rep 2006; 54: 1-40.

22 Hallstrand TS, Boitano LJ, Johnson WC, Spada CA, Hayes JG, Raghu G. The timed walk test as a measure of severity and survival in idiopathic pulmonary fibrosis. Eur Respir J 2005; 25: 96-103.

23 Silbiger SR, Neugarten J. The impact of gender on the progression of chronic renal disease. Am J Kidney Dis 1995; 25: 515-533.

24 Dai WJ, Jiang HC. Advances in gene therapy of liver cirrhosis: a review. World J Gastroenterol 2001; 7: 1-8.

25 Blush J, Lei J, Ju W, Silbiger S, Pullman J, Neugarten J. Estradiol reverses renal injury in Alb/TGF- $\beta 1$ transgenic mice. Kidney Int 2004; 66: 2148-2154.

26 Xu JW, Gong J, Chang XM, et al. Estrogen reduces CCL4induced liver fibrosis in rats. World J Gastroenterol 2002; 8: 883-887.

27 Yasuda M, Shimizu I, Shiba M, Ito S. Suppressive effects of estradiol on dimethylnitrosamine-induced fibrosis of the liver in rats. Hepatology 1999; 29: 719-727.

28 Gharaee-Kermani M, Hatano K, Nozaki Y, Phan SH. Gender-based differences in bleomycin-induced pulmonary fibrosis. Am J Pathol 2005; 166: 1593-1606.

29 Franks P, Clancy CM, Naumburg EH. Sex, access, and excess. Ann Intern Med 1995; 123: 548-550.

30 Lettieri CJ, Nathan SD, Barnett SD, Ahmad S, Shorr AF. Prevalence and outcomes of pulmonary arterial hypertension in advanced idiopathic pulmonary fibrosis. Chest 2006; 129: 746-752. 